\title{
Spatial patterns of recorded mastitis incidence and somatic cell counts in Swedish dairy cows: implications for surveillance
}

\author{
Cecilia Wolff ${ }^{1}$, Mark Stevenson ${ }^{2}$, Ulf Emanuelson ${ }^{1}$, Agneta Egenvall $^{1}$, Ann Lindberg ${ }^{3}$ \\ ${ }^{1}$ Department of Clinical Sciences, Swedish University of Agricultural Sciences, P.O. Box 7054, 75007 Uppsala, \\ Sweden; ${ }^{2}$ EpiCentre, Institute of Veterinary, Animal and Biomedical Sciences, Massey University, P.B. 11-222 \\ Palmerston North 4442, New Zealand; ${ }^{3}$ Department of Disease Control, National Veterinary Institute, SE-751 \\ 89 Uppsala, Sweden
}

\begin{abstract}
Clinical mastitis $(\mathrm{CM})$ is the most common veterinary treated disease in Swedish dairy cattle. To investigate if the distribution of veterinary registered cases of CM in Sweden follows that of the spatial distribution of cows with high somatic cell counts (SCCs), the spatial distribution of CM odds was estimated from available records and compared with udder health measures based on measurements of SCC derived from official milk recording. The study revealed areas with significantly lower odds for CM but with a high proportion of cows with a poor udder health score, suggesting an under-reporting of CM. We also found areas of significantly higher odds for CM despite a low proportion of cows with a poor udder health score, suggestive of over-treatment of mastitis. The results should enable targeted studies of reasons for discrepancies, e.g. farmers' and veterinarians' attitudes to mastitis treatment and disease recording in areas with a deficit or excess of registered CM cases. High quality disease records for dairy cattle are of interest not only for the dairy management but also for disease surveillance, monitoring of use of antibiotics and food safety purposes.
\end{abstract}

Keywords: bovine mastitis, surveillance, somatic cell count, spatial odds, Sweden.

\section{Introduction}

Spatial analysis has been used in a number of studies on the epidemiology, surveillance and monitoring of infectious diseases of animals (e.g. Stevenson et al., 2000; Perez et al., 2002; Ersbøll et al., 2010; Wheeler et al., 2010). This is a useful analytical technique allowing the identification of the environmental risk for disease, detection of anomalies in disease reporting and the monitoring of changes in the distribution of disease over time. To our knowledge, spatial analyses of production diseases in domestic animals are less common (Clements et al., 2005; Gay et al., 2006). Information on the spatial location of herds or individual animals is now routinely recorded in many countries and this provides an opportunity to expand spatial analyses to better understand the distribution and determinants of endemic disease.

\section{Corresponding author:}

Cecilia Wolff

Department of Clinical Sciences

Swedish University of Agricultural Sciences, P.O. Box 7054

75007 Uppsala, Sweden

Tel. +46 18 671-000; Fax +46 18 673-545

E-mail: cecilia.wolff@slu.se
In Sweden, the national disease recording system (NADRS) is administered by the Swedish Board of Agriculture. As Swedish dairy farmers are not allowed to treat clinical disease without previous, professional examination and treatment, any health event, e.g. clinical mastitis (CM), should be examined and diagnosed by a veterinarian before treatment is initiated (Anonymous, 2009). All Swedish veterinarians are obliged to report data on diseases they diagnose in cattle to the Swedish Board of Agriculture; either individually or at the group level. The report should include the identity of the herd and animal(s) within the herd, diagnosis, date on which the visit took place, details of any treatment(s) prescribed, details of recommended withdrawal period(s) and the veterinarian's unique identifier. By law, veterinarians must report details of all visits to the NADRS within one week following the date on which the animal(s) was (were) physically examined (Anonymous, 2000).

The Swedish official milk recording system (SOMRS) was developed in the 1970s and combines production data for cattle with recording scheme that includes disease data based on registrations made by veterinarians and also, to a lesser extent, directly by the farmers, a system unique to the Nordic countries (Andersson, 1988; 
Emanuelson, 1988; Olsson et al., 2001). For herds participating in the SOMRS, veterinary registration data are regularly transferred from the NADRS to the SOMRS and used by the farmers, herd advisors, and those working within research institutions.

The SOMRS provides data from a large proportion of the Swedish dairy cattle population in a cost efficient way and it has been used in several studies (Oltenacu et al., 1998; Hultgren et al., 2004; Carlen et al., 2005; Nyman et al., 2009). Earlier studies have shown that the SOMRS database does not include all clinical disease events nor all veterinary treated disease events applied to dairy cows (Mörk et al., 2009) and that the completeness of the disease information varies by geographic region (Mörk et al., 2010).

In dairy production the somatic cell count (SCC), i.e. then number of inflammatory cells per $\mathrm{ml}$ of milk, is used to diagnose both subclinical and clinical mastitis. As such, it is a measure of both udder health and milk quality. It can be measured for individual cows or in bulk milk from a herd. SCC data provides a more objective measure of udder health than veterinary registrations of $\mathrm{CM}$. The relationship between SCC and incidence of CM is well established (Dohoo et al., 1984; Harmon, 1994; Green et al., 2004). Thus, in theory, if the distributions of individual cow SCCs within a herd are skewed towards high values, it would be reasonable to expect that the incidence of CM within the herd should also be high. This being the case, a comparison of CM events recorded by veterinarians with SCC details recorded at each monthly herd test provides the opportunity to identify mismatches between the two measures. High SCC combined with a low CM score would be suggestive of under-ascertainment of mastitis cases by veterinarians whereas the opposite would be suggestive of over-ascertainment of cases, at least on an average or population level. Evaluation of the spatial distribution of herd-level SCC and CM details should then provide useful information in terms of identifying the uniformity of CM surveillance capacity across the country.

Our hypothesis for the current study was that the distribution of veterinary registered cases of CM in Sweden follows that of the spatial distribution of cows with high SCC. More specifically, our aim was to study if there were any regions with possible under-reporting of CM. Our approach was to estimate the spatial distribution of CM odds, as recorded in the SOMRS and then to compare this with udder health measures based on measurements of SCC derived from official milk recording.

\section{Material and methods}

\section{Herd data}

The study was carried out as a cross-sectional study, covering a full year. We retrieved annual production data at the herd level from the SOMRS database for all herds participating in milk recording for the period September 2008 up to and including August 2009. The udder disease (UD) score, i.e. the geometric mean of an individual cow's SCCs from the last three monthly milk tests, is one of the SOMRS udder health measures used to derive the herd level SCC status. This value is then adjusted for the effect of breed, lactation number, days in milk and milk yield (Brolund, 1985). The UD score is reported on a scale from zero to nine where values from six to nine are regarded as "poor" indicating that a cow is likely to have subclinical mastitis. The number of cows in a herd with poor UD score on at least one test milking, as well as the average monthly prevalence (in \%) of cows with poor UD score, were included in the data extract provided by the SOMRS.

The CM cases in the SOMRS are predominantly registered by veterinarians, and only a minor proportion of all CM cases are registered directly by the farmers. The SOMRS applies a 21-day lag period for the definition of a CM case. This means that all mastitis diagnoses registered for the same animal within 21 days from the first are treated as a single case. A case of subclinical mastitis, i.e. high SCC, diagnosed by a veterinarian should be registered in the SOMRS with a specific diagnostic code for subclinical mastitis. The incidence rate of CM (cases per 100 cow-years) and the cumulative incidence (number of cows) of CM during the study period were included in the data. These two measures were compared and considered interchangeable and we decided to use the cumulative incidence for further analysis.

Additional herd-level data included the average herd-size (in cow-years), calculated from the number of cow-days per herd and the geometric mean bulk milk SCC (BMSCC; cells per ml) calculated using each cow's monthly SCC. The data did not include registered cases of subclinical mastitis. Herds with a size of less than 25 cow-years or with incomplete data were excluded.

The geographical location of each study herd was retrieved from the Swedish Board of Agriculture as Cartesian coordinates in projection RT90 2.5 gon V (one of the standard map projections for Sweden). A total of 4,657 herds were included in the production 
data from the Swedish Dairy Association and of those 4,564 had coordinate data. In total, $83 \%$ of the herds $(3,851)$ met the inclusion criterion of a herd size of at least 25 cow-years. Four herds were removed because of identical coordinates with another (larger) herd. All data were entered into a relational database (Microsoft Access 2007, Microsoft Corp.). Data management was done using structured query language within Access.

\section{Descriptive analysis}

To visualise the spatial distribution of dairy cows in Sweden, a kernel smoothed density plot (Kelsall and Diggle, 1995) for stock numbers was produced using the density function implemented within the spatstat package (Baddeley and Turner, 2005) in $\mathrm{R}$ version 2.11.1 (R Development Core Team, 2010). A Gaussian kernel function with a fixed bandwidth of $30 \mathrm{~km}$ was used for these analyses. The bandwidth parameter for the kernel functions, used to control for the degree of smoothing of the estimated density surface, was calculated by cross validation (Bowman and Azzalini, 1997).

Spatial odds of CM and spatial distribution of poor UD score

Our first task was to describe the distribution of mastitis throughout Sweden, corrected for the spatial distribution of the dairy cattle population at risk. Two surfaces, representing the number of cattle per $\mathrm{km}^{2}$, were constructed using a Gaussian-kernel smoothing function implemented in the sparr package within R. The first (case) surface was based on all herds identified as CM-positive throughout the study period. The second (control) surface was based on all herds identified as CM-negative. For these analyses the coordinates of each herd defined its position in space and the number of cows (the total number of CM-positive cows for the case surface and the total number of CM-negative cows for the control surface) was used as a weighing variable. The grid cell resolution was 200, i.e. the length and breadth of Sweden were each divided into 200 segments.

The logarithm of the ratio of the case surface to the control surface (Kelsall and Diggle, 1995) provided an estimate of the spatial distribution of the CM (log) odds. In the northern-most part of Sweden, where dairy herds are sparse, the $(\log )$ odds estimates were of a non-reasonable magnitude, and for this reason this area was removed from the analyses. Thirty-three herds were located in this area, resulting in study population of 3,814 (82\% of all 4,657 herds in SOMRS) dairy herds.

Analyses were conducted in sparr version 0.2-1 (Davies et al., 2011) to test the hypothesis that the spatial distribution of CM odds was uniform across Sweden. This was done using a procedure based on the calculation of asymptotic P-values assigned to each grid cell of the surface and was based on the Z-test (Hazelton and Davies, 2009). This approach is an alternative to the computationally intensive calculation of point-wise p-values using Monte Carlo simulation (Diggle, 2003; Bivand et al., 2008). It takes into account the number of observations in an area and gives conservative $\mathrm{P}$-values in areas where data are sparse. This analysis allowed us to superimpose contour lines on the log odds surface, delineating areas of significantly depressed (or elevated) CM odds.

It was not possible to use the same approach to identify case and control herds to calculate (log) odds of poor udder health as indicated by poor UD score, because all herds had at least one cow with poor UD score on at least one test milking; hence there were no control herds.

Instead, two surfaces representing the number of cattle per $\mathrm{km}^{2}$ were constructed using a Gaussian-kernel smoothing function implemented in sparr. The first (numerator) surface was based on the number of cows with a poor UD score on at least one test milking. The second (denominator) surface was based on the total number of cattle in each herd. As before, the coordinates of each herd defined its position in space. As weighing variable the number of cows with a poor UD score on at least one test milking and the total number of cows in each herd were used for the numerator and the denominator surface, respectively. The ratio of the numerator surface to the denominator surface provided a relief map of the proportion of cattle per $\mathrm{km}^{2}$ with a poor UD score. For these analyses the same grid resolution and pilot bandwidth as used for the log RR of CM was used.

\section{Results}

In 2009 , approximately $85 \%$ of the dairy herds were enrolled in SOMRS while the NADRS, by design, has $100 \%$ coverage. The size and udder health parameters for study herds are presented in Table 1 . In total, the 3,814 study herds contributed 265,024 cow-years at risk. The number of cows with at least one test milking with a poor UD score was 109,749 and the cumulative incidence of $\mathrm{CM}$ was 37,148 . Of these, 36,539 
Table 1. Descriptive statistics of production parameters at herd-level for the study herds $(\mathrm{n}=3,814)$.

\begin{tabular}{|c|c|c|c|c|c|c|}
\hline & \multicolumn{3}{|c|}{$\begin{array}{l}\text { Herds with registered } \\
\text { clinical mastitis }(\mathrm{n}=3,355)\end{array}$} & \multicolumn{3}{|c|}{$\begin{array}{l}\text { Herds without registered } \\
\text { clinical mastitis }(n=459)\end{array}$} \\
\hline & $\mathrm{q} \cdot 10^{\mathrm{a}}$ & $\mathrm{q} \cdot 50^{\mathrm{a}}$ & $\mathrm{q} \cdot 90^{\mathrm{a}}$ & $\mathrm{q} \cdot 10^{\mathrm{a}}$ & $\mathrm{q} \cdot 50^{\mathrm{a}}$ & $\mathrm{q} \cdot 90^{\mathrm{a}}$ \\
\hline Average size (cow-years) & 30.9 & 54.8 & 132 & 28.6 & 45.3 & 114 \\
\hline Average bulk milk somatic cell count (1000 cells/ml) & 144 & 228 & 342 & 145 & 240 & 360 \\
\hline No. of cows with poor udder disease score at $\geq 1$ test milking & 10.0 & 22.0 & 58.0 & 8.0 & 17.0 & 47.2 \\
\hline Average monthly proportion of cows with poor udder disease (UD) score (\%) & 7.0 & 14.0 & 22.0 & 7.0 & 14.0 & 22.0 \\
\hline No. of cows with any registered clinical mastitis $(\mathrm{CM})$ & 2.0 & 7.0 & 24.0 & 0 & 0 & 0 \\
\hline Incidence rate of registered CM (cases per 100 cow-years) & 2.0 & 11.0 & 30.0 & 0 & 0 & 0 \\
\hline
\end{tabular}

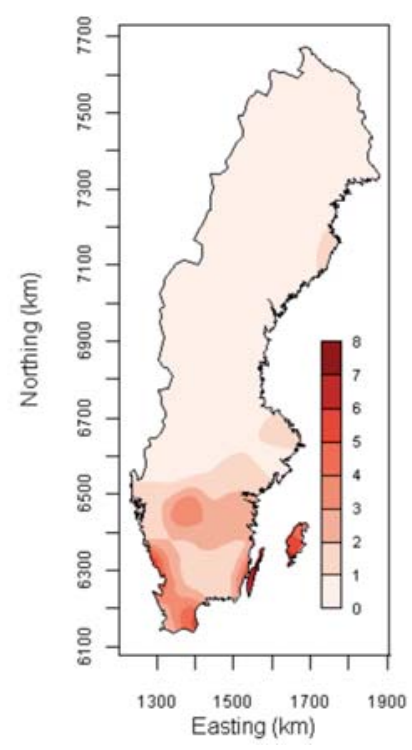

Fig. 1. Kernel smoothed density plot of stock numbers (cows per $\mathrm{km}^{2}$ ) of dairy cows in the study herds.

cases from 3,318 herds were veterinary registered and $609(1.6 \%)$ CM cases from 197 herds were farmer registered. There were 496 herds with no veterinary registered case of CM during the study period; of these 37 herds had farmer registered CM cases. The kernel smoothed density function of stock density (Fig. 1) shows the uneven distribution of the dairy cow population in Sweden with delimited dairy dense areas in the south including the two islands in the Baltic Sea.

We found areas with either significantly low or high $(\log )$ odds of cows with registered CM (Fig. 2). These areas did not follow the patterns of poor udder health, suggesting that there was a deficit of cows with $\mathrm{CM}$ cases in areas with low odds for cows with registered $\mathrm{CM}$ but with a high proportion of cows with a poor UD score (Fig. 3).

\section{Discussion}

There are four possible combinations of high or low odds of cows with registered CM and good or poor

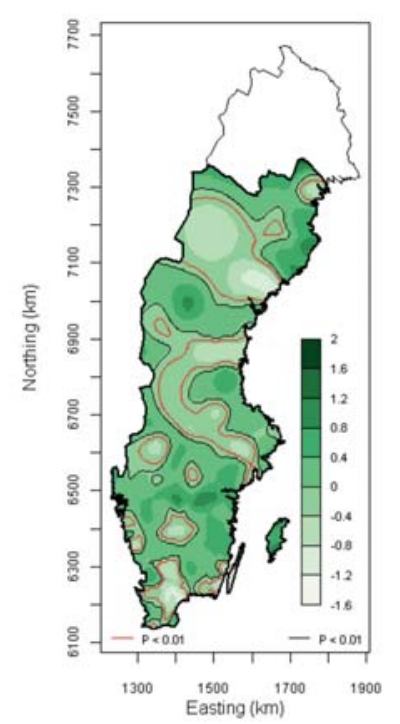

Fig. 2. Surface plot of the $(\log )$ odds of registered clinical mastitis $(\mathrm{CM})$ in Swedish dairy herds in milk recording. Contour lines delineates areas of significantly $(\mathrm{P}<0.01)$ decreased (red line) or increased (black line) odds for CM.

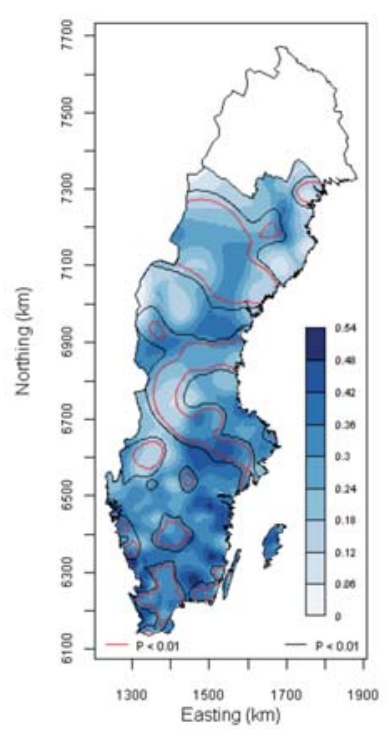

Fig. 3. Extraction map of the kernel smoothed intensity of cows with poor udder disease (UD) score on at least one test milking divided by the kernel smoothed intensity of stock numbers. The contours of significantly $(\mathrm{P}<0.01)$ decreased (red line) or increased (black line) odds for clinical mastitis (CM) are superimposed. 


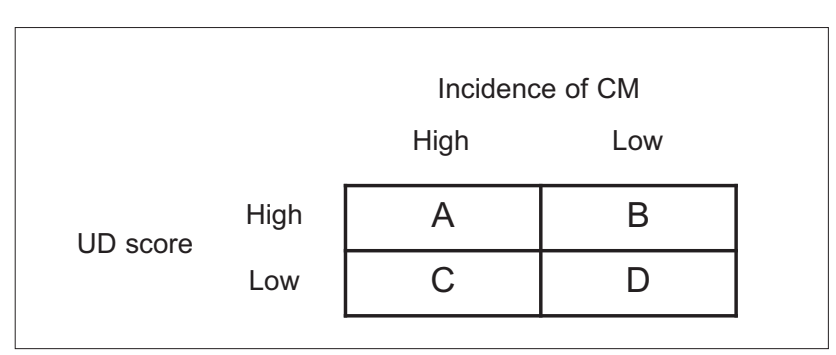

Fig. 4. Combinations of udder disease (UD) score and incidence of clinical mastitis (CM) that were possible in Swedish dairy cattle.

udder health (Fig. 4). Theoretically, good udder health should be reflected by cows with both a low incidence of CM and low UD scores (combination D). Conversely, poor udder health should be reflected by a high incidence of CM and high UD scores (combination A) (Dohoo et al., 1984; Harmon, 1994; Green et al., 2004). Discrepancies in either direction (high CM incidence - low UD score [combination C] and low $\mathrm{CM}$ incidence - high UD score [combination B]) are both anomalies.

The occurrence of one of these anomalies in our results, combination B in Figure 4, i.e. a poor udder health (as measured by a high UD score) but low incidence of CM, prompts us to reject the null hypothesis for this study, that the spatial distribution of veterinary registered cases of CM in Sweden follows that of the spatial distribution of cows with high SCC. This implies that there are regions of the country where the $\mathrm{CM}$ events are under-reported (Fig. 3). These findings are in agreement with those of Mörk et al. (2010) who found that the completeness of veterinary registered diagnostic events in the SOMRS database varied between regions.

Swedish veterinarians are obliged by law to report diagnoses and treatments on cattle to the Swedish Board of Agriculture within a week. State employed veterinarians (approximately $50 \%$ of all cattle practitioners) do this through their in-house developed computer system for record keeping and invoicing, which is also linked to their individual salaries. Private practitioners can use one of several approved software, which are usually combined with record keeping and invoicing, and the mandatory record information is submitted electronically to the SBA. Alternatively, private practitioners can use a paper-based system and submit hard copies of diagnoses and treatment details. The spatial locations of state and private practitioners were not available so any differences between types of practice (i.e. state employed veterinarians versus private practitioners) could not be spatially determined.

Veterinarians should examine and register all clini- cal disease events, obviously with the exception of events where the farmer chooses not to call for a veterinarian. The treatment threshold for individual farmers varies because of differences in attitudes to mastitis treatment (Jansen et al., 2009) and when detecting a cow with $\mathrm{CM}$ a farmer may not always necessarily decide to contact the veterinarian for treatment (Vaarst et al., 2002; Nyman et al., 2007). However, if farmers and veterinarians in all parts of the country act on average similarly upon noting or diagnosing $\mathrm{CM}$, the disease information in the SOMRS should reflect the same proportion of the true incidence of $\mathrm{CM}$ in all dairy herds enrolled in milk recording. Thus, the level of underreporting caused by farmers should be spatially homogenous; the opposite is suggested by the present study. However, differences in treatment thresholds could still be an explanation for areas conforming to combination $\mathrm{B}$ (low $\mathrm{CM}$ incidence and high UD score) in Figure 4, if there are regional differences in the mastitis management protocols promoted by veterinarians.

The geographical distribution of dairy cows in Sweden is strongly heterogeneous with small areas of the country containing relatively high proportions of the country's dairy cows (Fig. 1). If there is underreporting of CM in a dairy dense area this obviously has a larger impact than underreporting in a less dairy dense area. Underreporting in a dairy dense area could have a substantial impact on the number of cows with a mastitis history (too few cases). This would bias for example herd health measures and possibly also the genetic evaluations of mastitis resistance of dairy bulls which use mastitis data from SOMRS. In addition, one could legitimately question the data quality for other diagnoses in dairy cattle in areas with underreporting.

A low incidence of cows with $\mathrm{CM}$ in combination with good udder health (low UD score) (Fig. 4, combination D) represents a good agreement between surveillance systems and might be a result of a successful udder health work. Local livestock associations have specialised herd health veterinarians that conduct udder health consultancy work but also regular cattle practitioners are active in udder health programmes. On the other hand, a high incidence of CM in combination with good udder health (Fig. 3, combination C) suggests over-treatment of CM in such areas. In a study of high-yielding Swedish dairy herds with a low prevalence of subclinical mastitis, farmers managing herds with a high incidence of $\mathrm{CM}$ made the decision to contact veterinarian based on manifestation of less severe clinical signs compared with farmers managing herds with a low incidence of CM (Nyman et al., 2007). It is 
also possible that some veterinarians treat and record subclinical mastitis as $\mathrm{CM}$ which is a form of overtreatment if the cow is milking. The results from the present study could help target further studies of herd manager or veterinarian attitudes to mastitis treatment or campaigns aiming at reducing the use of antibiotics in areas with suspicion of over-treatment.

Combination $\mathrm{A}$ in Figure 4, i.e. a high incidence of $\mathrm{CM}$ and poor udder health (high UD score), represents a good agreement between surveillance systems, but is, of course, an undesirable situation in terms of milk quality. The spatial analysis applied here gives an opportunity to identify such areas as a target for further, more in-depth, studies to identify reasons for these shortcomings. One possible reason could be a lack of qualified cattle practitioners in such areas, and it would therefore be interesting to study also the spatial distribution of cattle practitioners in Sweden. If the distance to a veterinarian influences the incidence of veterinary reported mastitis and the herd SCC this may be an animal welfare issue. One could argue for the need of special support to farmers in remote areas if herd managers in these herds are reluctant to consult veterinarians for mastitis cases. If, on the other hand, farmers with more easily available veterinary services have less veterinary treated mastitis events one would like to know why.

The usefulness of milk recording is obvious in developed dairy production systems and several countries have established such recording systems (ICAR, 2011). In systems where the disease recordings are based on veterinary diagnoses and treatments like the SOMRS one may expect a higher and less varying quality of CM data than in systems where the farmer supplies disease data e.g. Australia (Anonymous, 2003a) and New Zealand (Anonymous, 2003b). A well-functioning system for disease recording for cattle has its use not only in herd management and breeding programmes but increases traceability from a food safety aspect and enables surveillance of emerging diseases. The SOMRS database is a secondary database, i.e. the information was not primarily collected for research purposes and the researcher has no control over the data collection. For researchers it would increase the quality of their studies if geographical differences in the quality of (mastitis) data in SOMRS were known and could be taken into account. Spatial analysis can be applied to understand geographical patterns of disease and as in the present study geographical patterns of disease recording. The results from the present study could be used to focus future studies of the disease recording system to regions with poor veterinary reporting and thus find ways to improve the recording system and the completeness of the disease data.

An alternative to the odds function and local (point wise) test of increased or decreased odds of CM would have been a global test of increased or decreased risk. This could for instance be performed by means of a spatial scan statistic (Kulldorff, 1997). We chose to use the non-parametric approach implemented within the sparr package because it is not limited to circular or elliptical windows of increased or decreased risk as the scan statistic, and because the results include the odds at each point in the study area.

In conclusion, the present study showed that there were areas in Sweden with significantly lower odds of registered $\mathrm{CM}$, where udder health, as measured by UD score, was not better compared to areas with higher odds of CM. This discrepancy could be caused by poor reporting by veterinarians or by farmers having a systematically higher threshold for consulting a veterinarian for therapy in such areas. The spatial distribution of poor udder health is useful to identify areas in need for further actions.

\section{Acknowledgements}

The authors would like to acknowledge the Swedish Dairy Association for providing the SOMRS data, the Swedish Board of Agriculture for providing the coordinate data, the Swedish Research Council Formas and Carls Fredrik von Horn's fund for financial support.

\section{References}

Andersson L, 1988. Swedish dairy herd health programmes based on routine recording of milk production, fertility data, somatic cell counts and clinical diseases. Proceedings of the Sixth International Congress on Animal Hygiene, 190-193.

Anonymous, 2000. SJVFS 2000: 114, Föreskrifter om ändring i Statens Jordbruksverks föreskrifter (SJVFS 1998: 38) om journalföring, uppgiftslämnande m.m., Saknr D 30. Swedish Board of Agriculture, Jönköping, Sweden.

Anonymous, 2003a. Data interchange format. In (Ed. ADHISP Ltd), Melbourne, Australia.

Anonymous, 2003b. MINDA health. In (Ed. LI Corporation), Hamilton, NZ.

Anonymous, 2009. SJVFS 2010: 17, Föreskrifter om ändring i Statens Jordbruksverks föreskrifter (SJVFS 2009: 84) om veterinärers rätt att förskriva och tillhandahålla läkemedel i anslutning till djursjukvård och djurhälsovård, Saknr D 9. Swedish Board of Agriculture, Jönköping, Sweden.

Baddeley A, Turner R, 2005. Spatstat: an R package for analy- 
zing spatial point patterns. J Stat Soft 12, 1-42.

Bivand R, Pebesma E, Gómez-Rubio V, 2008. Applied Spatial Data Analysis with R. Springer Verlag, London, UK.

Bowman A, Azzalini A, 1997. Applied Smoothing Techniques for Data Analysis: The Kernel Approach with S-PLUS Illustrations. Oxford University Press, London, UK.

Brolund L, 1985. Cell counts in bovine milk, causes of variation and applicability for diagnosis of subclinical mastitis. Acta Vet Scand, 123.

Carlen E, Schneider MD, Strandberg E, 2005. Comparison between linear models and survival analysis for genetic evaluation of clinical mastitis in dairy cattle. J Dairy Sci 88, 797803.

Clements ACA, Pfeiffer DU, Hayes D, 2005. Bayesian spatiotemporal modelling of national milk-recording data of seasonal-calving New Zealand dairy herds. Prev Vet Med 71, 183196.

Davies TM, Hazelton ML, Marshall JC, 2011. sparr: Analyzing spatial relative risk using fixed and adaptive kernel density estimation in R. J Stat Softw 39, 1-14.

Diggle PJ, 2003. Statistical Analysis of Spatial Point Patterns. Arnold, London, UK.

Dohoo IR, Meek AH, Martin SW, 1984. Somatic cell counts in bovine milk - relationships to production and clinical episodes of mastitis. Can J Comp Med 48, 130-135.

Emanuelson U, 1988. The national Swedish animal disease recording system. Acta Vet Scand 84, 262-264.

Ersbøll AK, Ersbøll BK, Houe H, Alban L, Kjeldsen AM, 2010. Spatial modelling of the between-herd infection dynamics of bovine virus diarrhoea virus (BVDV) in dairy herds in Denmark. Prev Vet Med 97, 83-89.

Gay E, Barnouin J, Senoussi R, 2006. Spatial and temporal patterns of herd somatic cell score in France. J Dairy Sci 89, 24872498.

Green MJ, Green LE, Schukken YH, Bradley AJ, Peeler EJ, Barkema HW, de Haas Y, Collis VJ, Medley GF, 2004. Somatic cell count distributions during lactation predict clinical mastitis. J Dairy Sci 87, 1256-1264.

Harmon RJ, 1994. Physiology of mastitis and factors affecting somatic cell counts. J Dairy Sci 77, 2103-2112.

Hazelton ML, Davies TM, 2009. Inference based on Kernel estimates of the relative risk function in geographical epidemiology. Biometrical J 51, 98-109.

Hultgren J, Manske T, Bergsten C, 2004. Associations of sole ulcer at claw trimming with reproductive performance, udder health, milk yield, and culling in Swedish dairy cattle. Prev Vet Med 62, 233-251.

ICAR, 2011. International Committee for Animal Recording home page (http://www.icar.org; accessed on January 2011).

Jansen J, van den Borne BHP, Renes RJ, van Schaik G, Lam
TJGM, Leeuwis C, 2009. Explaining mastitis incidence in Dutch dairy farming: the influence of farmers' attitudes and behaviour. Prev Vet Med 92, 210-223.

Kelsall JE, Diggle PJ, 1995. Nonparametric-estimation of spatial variation in relative risk. Stat Med 14, 2335-2342.

Kulldorff M, 1997. A spatial scan statistic. Commun Stat ATheor 26, 1481-1496.

Mörk M, Lindberg A, Alenius S, Vagsholm I, Egenvall A, 2009. Comparison between dairy cow disease incidence in data registered by farmers and in data from a disease-recording system based on veterinary reporting. Prev Vet Med 88, 298307.

Mörk MJ, Wolff C, Lindberg A, Vagsholm I, Egenvall A, 2010. Validation of a national disease recording system for dairy cattle against veterinary practice records. Prev Vet Med 93, 183-192.

Nyman AK, Emanuelson U, Gustafsson AH, Persson Waller K, 2009. Management practices associated with udder health of first-parity dairy cows in early lactation. Prev Vet Med 88, 138-149.

Nyman AK, Ekman T, Emanuelson U, Gustafsson AH, Holtenius K, Waller KP, Sandgren CH, 2007. Risk factors associated with the incidence of veterinary-treated clinical mastitis in Swedish dairy herds with a high milk yield and a low prevalence of subclinical mastitis. Prev Vet Med 78, 142160.

Olsson SO, Baekbo P, Hansson SO, Rautala H, Osteras O, 2001. Disease recording systems and herd health schemes for production diseases. Acta Vet Scand 94, 51-60.

Oltenacu PA, Hultgren J, Algers B, 1998. Associations between use of electric cow-trainers and clinical diseases, reproductive performance and culling in Swedish dairy cattle. Prev Vet Med 37, 77-90.

Perez AM, Ward MP, Torres P, Ritacco V, 2002. Use of spatial statistics and monitoring data to identify clustering of bovine tuberculosis in Argentina. Prev Vet Med 56, 63-74.

R Development Core Team, 2010. R: a language and environment for statistical computing. R Foundation for Statistical Computing, Vienna, Austria.

Stevenson MA, Wilesmith JW, Ryan JBM, Morris RS, Lawson AB, Pfeiffer DU, Lin D, 2000. Descriptive spatial analysis of the epidemic of bovine spongiform encephalopathy in Great Britain to June 1997. Vet Rec 147, 379-384.

Vaarst M, Paarup-Laursen B, Houe H, Fossing C, Andersen HJ, 2002. Farmers' choice of medical treatment of mastitis in Danish dairy herds based on qualitative research interviews. J Dairy Sci 85, 992-1001.

Wheeler DC, Waller LA, Biek R, 2010. Spatial analysis of feline immunodeficiency virus infection in cougars. Spat Temp Epidemiol 1, 151-161. 